\section{China must publicize its emissions reports}

As China is the world's largest energy consumer and carbon dioxide emitter, the future trajectory of its carbon emissions will play a crucial part in global mitigation plans. However, China's National Assessment Reports on Climate Change, issued in 2007 and 2011, are limited in scope and not widely disseminated or cited. These shortcomings must be rectified before the next report is released this year.

Compared with the assessment reports by the Intergovernmental Panel on Climate Change (IPCC), China's have had scarcely any impact. The IPCC report is cited thousands of times in United Nations official documents, whereas China's seem to be barely mentioned even in Chinesegovernment documents.

In our view, this low impact reflects the general lack of public interest in climate change in China, the paucity of media coverage and scholarly study, and the insufficient efforts by central and local government to reduce energy consumption and greenhouse-gas emissions.

China's next assessment report needs to be more widely promoted, include more highquality research results, and objectively evaluate current policies to tackle climate change in the country. China should learn from the IPCC and open the way to international collaboration in preparing and promoting the country's assessment reports.

Yuan-Feng Wang,Yu-Rong Zhang Beijing Jiaotong University, China.

cyfwang@bjtu.edu.cn

\section{Biomedicine must look beyond $P$ values}

Establishing statistical validity for study findings goes beyond a consideration of $P$ values alone (R. Nuzzo Nature 506, 150-152;
2014). In the era of big data, we now have many biological measures available for assessing how likely findings are to be true positives.

This more-comprehensive approach has long been used by epidemiologists to address concerns about bias and causality: for example, in investigations of possible components of hypothetical disease-causing pathways (L. H. Kuller et al. Am. J. Epidemiol. 178, 1350-1354; 2013). A way of inferring a causal association is to apply Hill's criteria, which seek ties between many factors, such as dose response, temporality and disease exposure (A. B. Hill Proc. R. Soc. Med. 58, 295-300; 1965).

Advances in genomics and systems biology enhance our capacity for such investigations.

We can now determine whether findings operate in a specific genotype context or fit biologically plausible pathways or networks - as was done in a re-evaluation of results from a genome-wide association study for multiple sclerosis (International Multiple Sclerosis Genetics Consortium Am. J. Hum. Genet. 92, 854-865; 2013). Anne-Louise Ponsonby Murdoch Childrens Research Institute, Parkville, Victoria, Australia. anne-louise.ponsonby@mcri. edu.au

Terence Dwyer International Agency for Research on Cancer, Lyon, France.

\section{Road maps of no use to some physicists}

We do not believe that it is feasible for a single organization to draw up a 'road map' for future lightand neutron-source facilities in the way that CERN does for the particle-physics community (see P. G. Radaelli Nature 505, $607-609 ; 2014)$. The diversity of the communities that use these facilities makes the centralization of scientific priorities impossible.

A range of research fields will benefit from Europe's investments in the X-ray Free Electron Laser and the European Spallation Source (ESS), and hundreds of scientists are collaborating to define ESS's capabilities and instrumentation (see go.nature.com/ip6afc).

Cassandras abound at the start of any large project that pushes the technological envelope, but the ESS is expected to boost scientific performance for neutron studies by as much as 300 -fold, opening up entirely new fields of science.

Because the ESS forms part of a wider network of neutron and light sources, the discussion needed in Europe is how to leverage and integrate these sources most effectively to improve our research and economic environment.

Aleksandar Matic Chalmers University of Technology,

Gothenburg, Sweden.

Peter Böni Technische

Universität München, Germany. Adrian Goldman University of Leeds, UK.

a.goldman@leeds.ac.uk

\section{End education meddling in Nepal}

The Nepalese government's backtracking last month on its political patronage of academia (Nature 506, 279; 2014) raises hopes that appointments to top university positions will soon be made by non-political committees of scholars. Such a move would ensure the selection of senior academics on merit, rather than political affiliation; these individuals would help to attract much-needed funding for education and research.

The Nepalese government needs to create an educational system that is free of political meddling and nepotism. The country's young scientists will return from abroad only when a proper infrastructure is in place that will enable them to implement their skills and to realize their ambitions in a merit-based society.
Kosh P. Neupane Tufts University, Medford, Massachusetts, USA. koshalnp@hotmail.com

\section{Fight floods on a global scale}

Accurate digital elevation models (DEMs) created using airborne lidar have transformed regional flood modelling and forecasting. At continental and global scales, however, the best-available DEMs come from satellite images and are too crude for simulating flooding — and its related risks to public health, biogeochemical cycling and wetland ecology. We would like to see industry, governments and humanitarian agencies come together to support the development of a global DEM with higher resolution and accuracy.

Current global DEMs cannot resolve the detail of terrain features that control flooding. More-effective flood-hazard maps could be created by obtaining high-resolution stereo images from satellites, combined with the latest advances in flood modelling using supercomputers. By 2050, worldwide annual losses due to flooding are predicted to reach US $\$ 1$ trillion (S. Hallegatte et al. Nature Clim. Change 3, 802-806; 2013). A global-scale DEM would have an enormous impact on finance (such as flood re-insurance), humanitarian services (such as disaster relief) and scientific research.

The advanced global DEM would use existing lidar data and stereo satellite images, and new lidar elevation data would be acquired on board disaster-relief aircraft or on drones deployed over flood plains. The operation costs would therefore be substantially cheaper than most satellite missions.

Guy J.-P. Schumann* NASA Jet Propulsion Laboratory, Pasadena, California, USA.

guy.j.schumann@jpl.nasa.gov

${ }^{\star}$ On behalf of 4 co-signatories; see go.nature.com/j1pchz for full list. 